\title{
POLÍTICAS PÚBLICAS dO ESTADO DE SÃO PAULO E A SOCIEDADE CIVIL ORGANIZADA NO ENFRENTAMENTO DOS IMPACTOS DA COVID-19 SOBRE OS SISTEMAS ALIMENTARES: O CASO DO PLANSAN-SP
}

\author{
Rodrigo Machado Moreira ${ }^{1}$ \\ Karina Rúbia Nunes ${ }^{2}$ \\ José Giacomo Baccarin ${ }^{3}$ \\ Beatriz Stamato ${ }^{4}$
}

\begin{abstract}
Resumo
O artigo apresenta prováveis impactos advindos da COVID-19 sobre os cinco componentes do sistema alimentar: organizações sociais; mercados; ciência e tecnologia; natureza (entorno biofísico); e políticas públicas. Investiga quais propostas contidas no Plano Estadual de Segurança Alimentar e Nutricional do Estado de São Paulo (PLANSAN-SP) podem responder a estes impactos, amenizando-os. Os impactos da COVID-19 nos sistemas alimentares são amplos e profundos, considerando as diversas realidades levantadas pela pesquisa bibliográfica. Esses impactos atingem diretamente o consumo de alimentos da população a partir das dinâmicas de quarentena adotadas mundo afora, sob diversas formas, com efeitos negativos no acesso e na disponibilidade de alimentos a curto, médio e longo prazos. O PLANSAN-SP contém diversas propostas para a garantia do Direito Humano a Alimentação Adequada e que estimulam Soberania Alimentar e a Segurança Alimentar e Nutricional. A análise realizada evidencia que o diálogo entre a sociedade civil organizada e o poder público é fundamental para a construção de propostas ajustadas a uma diversidade de desafios e realidades presentes no Estado de São Paulo e que o PLANSAN-SP, poderia responder positivamente aos impactos da COVID-19 no sistema alimentar paulista.
\end{abstract}

Palavras-Chave: COVID-19, PLANSAN-SP; Sistema Alimentar; Política Pública; Segurança Alimentar e Nutricional

\section{Introdução}

Os impactos advindos da COVID 19 sobre os sistemas alimentares no mundo e no Brasil são evidentes. O rendimento do trabalho médio do trimestre fevereiro-abril, que tinha alcançado um máximo, em 2014, no Brasil, de R \$1.030,7/mês, depois apresentou comportamento errático e, em 2019, foi de R\$1.026,4. Em igual período, em 2020, ainda sem a manifestação plena dos

\footnotetext{
${ }^{1}$ Pesquisador de Pós-Doutorado no Centro de Ciência e Tecnologia para a Soberania e a Segurança Alimentar e Nutricional (INTERSSAN/UNESP de Botucatu. rodrigo@mutuando. Org.br. ORCID: 0000-0001-54621476.

${ }^{2}$ Pesquisadora Associada ao INTERSSAN - Karina.rubia@unesp.br. ORCID: 0000-0002-2888.

3 Professor da UNESP de Jaboticabal e pesquisador associado do INTERSSAN - jose.baccarin@unesp.br. ORCID: 0000-0002-8120-3621.

${ }^{4}$ Professora da Faculdade Galileu e pesquisadora de pós-graduação do INTERSSAN/UNESP de Botucatu bia@mutuando.org.br-ORCID: 0000-0002-4147-3424.
} 
efeitos da pandemia, este valor caiu para $\mathrm{R} \$ 999,6$ (INSTITUTO BRASILEIRO DE GEOGRAFIA E ESTATISTICA, 2020a).

O agravante é que os preços relativos dos alimentos continuaram crescendo em 2020, aos moldes do que se verificava anteriormente. De 2007 a 2019, o Índice de Preços ao Consumidor Amplo (IPCA) aumentou 103,5\%, enquanto um dos seus nove grupos, o Índice de Preços de Alimentação e Bebidas (IPAB), expandia-se em 155,7\%. Já de janeiro a abril de 2020, enquanto o IPCA elevava-se em $0,2 \%$, o IPAB crescia $3,5 \%$, fato que vem fugindo do observado no mercado mundial agrícola, com preços atualmente em decréscimo (FOOD AND AGRICULTURE ORGANIZATION, 2020c; IBGE, 2020b).

Além dos impactos negativos na demanda ou consumo, têm-se verificado impactos desfavoráveis na oferta ou produção de alimentos. Frente a isso, uma série de ações vem sendo organizadas pelos países, na tentativa de mitigar o impacto dessa pandemia nos sistemas alimentares (FAO, 2020a).

O artigo lança luz sobre as propostas contidas no Plano Estadual de Segurança Alimentar e Nutricional do Estado de São Paulo (PLANSAN-SP), elaborado participativamente, entre julho e dezembro de 2018 pela CAISAN - Câmara Intersecretarial de Segurança Alimentar e Nutricional do Estado de São Paulo.

Como parte do Sistema Nacional de Segurança Alimentar e Nutricional (SISAN ${ }^{5}$ ), o Plano foi construído no Estado de São Paulo em diálogo envolvendo o Conselho Estadual de Segurança Alimentar e Nutricional (CONSEA-SP) e assessoria técnica do INTERSSAN Centro de Ciência e Tecnologia para a Soberania e Segurança Alimentar e Nutricional da UNESP, a partir de um Comitê Técnico formalizado pelo Governo do Estado.

O PLANSAN-SP possui diversas propostas para a garantia do Direito Humano a Alimentação Adequada - DHAA e que estimulam a Soberania e Segurança Alimentar e Nutricional - SSAN no Estado, frutos de duas conferências estaduais de SAN, com participação

\footnotetext{
${ }^{5}$ O SISAN envolve uma visão do sistema alimentar no Brasil que é sistêmica, intersetorial e que leva em conta uma agricultura sensível à nutrição e vem sendo implementado por meio de legislação nacional multissetorial, sendo considerado uma aparto estatal que demonstrou sucesso na melhoria do estado nutricional da população por meio de ações integradas (MALUF, 2015). O SISAN é composto por: conselho (CONSEA - como espaço intersetorial com representantes da sociedade civil e governos), onde se discutem, projetam e avaliam programas e ações relacionados à SAN; a Câmara Interministerial (CAISAN), órgão governamental com a missão de coordenar ações dos poderes executivos; a Conferência de Segurança Alimentar e Nutricional; e os planos de segurança alimentar. O SISAN é um sistema de adesão voluntária para estados e municípios (BRASIL, 2010). O CONSEA Nacional foi extinto em 01 de janeiro de 2019 (CASTRO, 2019), assim como o CONSEA-SP teve suas ações paralisadas durante todo o ano de 2019, até entrar em vacância em outubro de 2019.
} 
de diversos atores sociais de diferentes territórios de São Paulo, entre representantes da sociedade civil organizada e do poder público.

O objetivo deste artigo, a partir do levantamento dos impactos da pandemia do novo coronavírus (SARS COV 2) sobre o sistema alimentar no mundo, é investigar, neste momento de crise, como as propostas contidas no PLANSAN-SP ${ }^{6}$ podem contribuir para o enfrentamento destes impactos em escala local.

\section{Metodologia}

Este trabalho tomou como referência dois documentos principais, o Plano Estadual de Segurança Alimentar e Nutricional e o documento do United Nations System Standing Committee on Nutrition (UNSCN), que trata das evidências que indicam a necessidade de que se invista na transformação dos Sistemas Alimentares para melhorar a nutrição (UNITED NATIONS SYSTEM STANDING COMMITTEE ON NUTRITION, 2016) e para discutir a atual conjuntura social frente aos desafios da COVID-19 e os cenários futuros. Foi realizada uma busca não sistemática de artigos e reportagens, usando o buscador do Google, utilizando como palavras chaves COVID-19, PLANSAN-SP; Sistema Alimentar; Política Pública; Segurança Alimentar e Nutricional. Outras referências foram indicadas por especialistas. Também foram incluídos dados obtidos em bases nacionais (IBGE, 2020a,b).

As perguntas norteadoras para a seleção dos documentos foram: "Quais os impactos da pandemia do COVID-19 sobre um dos cinco componentes dos sistemas alimentares saudáveis propostos pelo UNSCN e quais propostas do PLANSAN podem responder aos problemas criados pela pandemia"?

Assim, o trabalho foi referenciado na dinâmica e complexidade dos sistemas alimentares. Os sistemas alimentares abarcam a conversão dos recursos naturais e esforços humanos em alimentos que sustentam a vida. As etapas da "produção ao prato" incluem o plantio, o crescimento e cuidado com a produção, a colheita, o processamento, o envase, a

\footnotetext{
${ }^{6}$ As propostas do PLANSAN-SP foram construídas socialmente para tornar o sistema alimentar mais sustentável em São Paulo. Sistemas alimentares são sustentáveis quando atendem às necessidades humanas presentes e futuras nas escalas local, regional e global, a partir de indicadores ligados a manutenção dos ciclos vitais e do equilíbrio ecológico dos agroecossistemas, dos conhecimentos e identidades locais ligadas ao manejo sustentável dos recursos naturais, do metabolismo energético equilibrado (fluxos de matéria e energia) nos agroecossistemas, da paisagem, da participação/inclusão social, entre outros. São atributos de um sistema alimentar sustentável, ainda, a diversidade, a equidade, a estabilidade, a produtividade total e a resiliência (TELLO; GONZALES DE MOLINA, 2017).
} 
distribuição, a publicidade, o comércio e a destinação dos resíduos. Isto é conhecido como suprimento/disponibilização de alimentos (UNSSCN, 2016).

Essa rede de abastecimento pode envolver desde cadeias de suprimentos complexas até as mais simples, como as de produção local. Já o lado da demanda ou do consumo envolve muitos determinantes, tais como o preço e a capacidade financeira do consumidor, o local de consumo, as preferências do consumidor, o conhecimento, os sabores, os hábitos culturais e as percepções dos consumidores. As políticas públicas e privadas, que investem esforços e recursos para o funcionamento dos sistemas alimentares, podem fazer desses dois conjuntos mais ou menos saudáveis e nutritivos (UNSSCN, 2016).

Para analisar o impacto da pandemia nos sistemas alimentares será utilizado o marco proposto pela United Nations System Standing Committee on Nutrition (2016), que define os cinco componentes dos sistemas alimentares que precisam ser analisados e monitorados: 1) organizações sociais; 2) mercados; 3) ciência e a tecnologia; 4) natureza (entorno biofísico); e 5) políticas públicas, como ilustrado na Figura 1.

Figura 1. Marco de avaliação dos efeitos ligados ao sistema alimentar

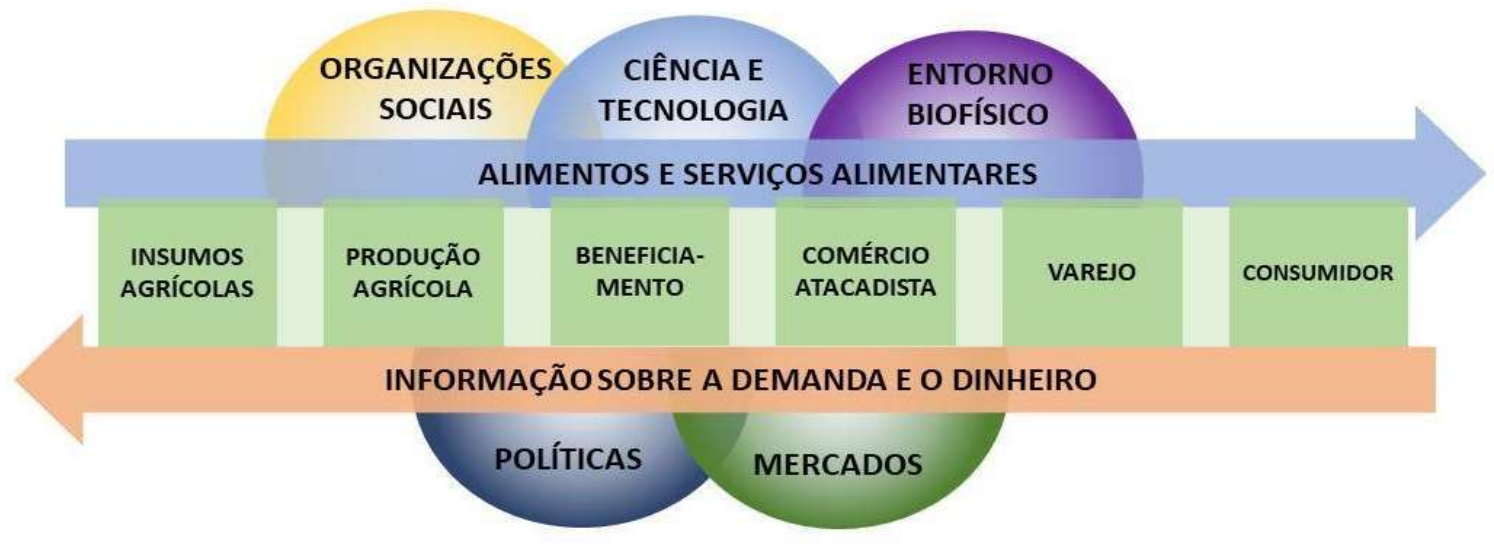

Fonte: Elaboração própria com base em UNSSCN (2016).

A tabela 1 apresenta os componentes e temas/subcomponentes do marco de avaliação, utilizados para orientar as buscas bibliográficas sobre os impactos da COVID 19 nos sistemas alimentares.

Tabela 1. Componentes e subcomponentes do Sistema Alimentar

\begin{tabular}{l|l}
\hline $\begin{array}{l}\text { Componente do Sistema } \\
\text { Alimentar }\end{array}$ & \multicolumn{1}{|c}{ Sub-componentes do Sistema Alimentar } \\
\hline Organizações Sociais & $\begin{array}{l}\text { Educação; mídias; estrutura doméstica; movimentos sociais; } \\
\text { sistema de vigilância sanitária. }\end{array}$ \\
\hline
\end{tabular}




\begin{tabular}{l|l}
\hline Mercados & $\begin{array}{l}\text { Preferências de alimentos; Estrutura de mercado; Competição; } \\
\text { Comércio Local; Comércio global; Salários. }\end{array}$ \\
\hline Ciência e Tecnologia & $\begin{array}{l}\text { Ciência e tecnologias agrícolas; tecnologias de processamento, } \\
\text { distribuição, transporte, armazenamento, tecnologias médicas. }\end{array}$ \\
\hline $\begin{array}{l}\text { Natureza (entorno } \\
\text { biofísico) }\end{array}$ & \begin{tabular}{l} 
Solo, água, clima, plantas, animais, nutrientes. \\
\hline Políticas Públicas
\end{tabular} \\
$\begin{array}{l}\text { Política Agrícola; Política de alimentação e nutrição; políticas } \\
\text { comerciais e laborais; Políticas ambientais; Saúde; e Segurança } \\
\text { Alimentar. }\end{array}$ \\
\hline
\end{tabular}

Fonte: UNSSCN, 2016.

Na tentativa de compreender o sistema alimentar como um todo, Nesheim et al. (2015) destaca ser importante compreender que se trata de um sistema não apenas complexo, mas também adaptativo, envolvendo características como atores individuais adaptativos, interdependência e retroalimentação, heterogeneidade, complexidade espacial e dinâmica. Dessa forma, ao descrever os impactos é importante ter em conta que um componente está relacionado aos demais componentes e não existem efeitos, ao final, que possam ser verificados de forma isolada.

\section{Resultados e Discussão}

As pandemias que a humanidade experimentou tiveram grande impacto na economia, no meio ambiente e em qualquer atividade humana, como criação de animais, agricultura, turismo, transporte, educação, saúde, pesca, mineração, indústria, comércio, serviços etc. Com a COVID-19 não é diferente. Existem evidências suficientes para afirmar que essa pandemia tem um efeito importante na agricultura e na disponibilidade de alimentos, afetando a demanda e a segurança alimentar da população mais vulnerável (SICHE, 2020; FAO, 2020a).

\section{COVID-19 nas Organizações Sociais e equipamentos públicos de proteção social}

Para as organizações sociais do Sistema Alimentar, a COVID-19 trouxe um grande desafio que é o aumento da pobreza no mundo, à medida em que as crises sanitária e econômica avançam. Essa pandemia tem potencial de acrescer cerca de 500 milhões de pessoas aos níveis já alarmantes de pobreza e consequente aumento da insegurança alimentar (SUMNER; HOY; ORTIZ-JUAREZ, 2020).

Nos Estados Unidos, o número de lares preocupados com a insegurança alimentar multiplicou-se por dez durante a pandemia, em comparação com a mesma pesquisa realizada 
antes da pandemia, com boa parte dos entrevistados indicando que foi ajudado por programas de doações de alimentos de governos e sociedade civil. Na China, apesar da incidência menor do temor da insegurança alimentar que nos Estados Unidos, também houve aumento no temor pela insegurança alimentar, especialmente nas classes sociais de menor renda. Nos Estados Unidos, a desconfiança dos entrevistados sobre a capacidade de funcionamento do sistema alimentar aumentou radicalmente, de $25 \%$ para $75 \%$, no transcurso da pandemia (DOU et al., 2020).

Efetivamente, os riscos de agravamento da insegurança alimentar são devidos à perda de renda de trabalhadores, ao isolamento social e acesso restrito aos mercados de alimentos, ao fechamento ou capacidade reduzida de organizações/instituições que apoiam redes de SAN, como bancos de alimentos e programas de alimentação escolar, e à desorganização das cadeias de suprimentos alimentares, além do desperdício de verduras, legumes, frutas e leite por dificuldades de colheita e transporte dos locais de produção até os de consumo (STEPHENS; MARTIN; VAN WIJK, 2020).

$\mathrm{Na}$ Ásia, os impactos da COVID-19 foram sentidos logo no início da pandemia, especialmente no sudeste asiático. É o caso dos trabalhadores rurais migrantes na China. Após o lockdown chinês, os trabalhadores que conseguiram retornar para as zonas rurais de onde são oriundos, se viram numa situação difícil. Por sua vez, em Mianmar, a garantia do governo de que compensaria o fechamento das fronteiras com a distribuição de alimentos, foi recebida com desconfiança pelas organizações sociais do país (FRANCO, 2020).

É importante relembrar que estamos analisando os impactos de uma pandemia num mundo onde cerca de 5,3 milhões de crianças morrem todos os anos por falta de assistência social ou médica e onde mais de um milhão de pessoas vivem em campos de concentração de refugiados de guerras e de avanços da grilagem de terras para expansão agrícola em diversas partes do mundo. A COVID-19 vem mostrando que os esforços para remediar a saúde da população não serão suficientes para aliviar os efeitos da crise econômica em marcha que afetará populações já vulneráveis, especialmente no campo (FRANCO, 2020).

Tanto quanto o poder público, a sociedade civil está altamente sob pressão. Há ações múltiplas registradas na imprensa, mas ainda pouco sistematizadas pela pesquisa científica. Assim, entidades sociais de caridade e bancos de alimentos, por exemplo, estão sob pressão pelo aumento acentuado da demanda, pela dificuldade de mão de obra e pelas diminuições de doações de alimentos ou de apoio governamental (NICOLA et al., 2020; POWER et al., 2020). 
Há muitas ações da sociedade civil organizada. A cooperação e o apoio mútuo estão em alta. Um exemplo é a iniciativa intitulada "A Cidade contra o Coronavírus" que permite o cadastramento de indivíduos e instituições assistenciais que precisam de ajuda durante a crise da COVID-19, no município de Botucatu-SP, Brasil.

Por meio do site www.acidadecontraocoronavirus.com.br, os doadores podem se cadastrar para ajudar de várias formas e, de forma autogestionária, são eles que definem como querem apoiar uma família ou entidade cadastrada para receber apoio. Ou seja, é o/a doador/a quem define a forma de ajudar, em comum acordo e a partir das necessidades do receptor desse auxílio. A iniciativa se deu, inicialmente, por meio da parceria do Instituto Giramundo Mutuando junto a empresa de TI local Solutudo, envolvendo outras parcerias com a sociedade civil, conselhos e governo local, para legitimação e divulgação do sistema no município (INSTITUTO GIRAMUNDO MUTUANDO, 2020) ${ }^{7}$.

Outros equipamentos de SAN estão sendo igualmente demandados, como restaurantes populares. No caso do Bom Prato, no Estado de São Paulo, os municípios foram autorizados a conveniar com esse programa estadual para adquirir marmitas de almoço e cafés da manhã, no intuito de diminuir as sobras, ao mesmo tempo em que alimenta, com qualidade, a população vulnerável do Estado de São Paulo (ARAUJO; MORAES, 2020).

Há outras iniciativas que conectam quem tem fome com quem tem alimentos já preparados para serem doados de forma segura, tais como restaurantes e cozinhas industriais, entre outros. Como exemplo, destaca-se a Plataforma "Comida Invisível" no sítio: www.comidainvisível.com.br.

No caso do Brasil, há clamores claros pela retomada do Programa de Aquisição de Alimentos (PAA), visando recompor estoques mínimos de produtos básicos e apoio às organizações que trabalham com doação de alimentos e produtores familiares (ARTICULAÇÃO NACIONAL DE AGROECOLOGIA, 2020), sendo que a agricultura familiar é um setor fundamental para SAN e o lócus ideal para a agricultura sustentável (CARMO, 1998).

\footnotetext{
${ }^{7}$ Segundo os organizadores do sistema "A Cidade Contra o Coronavirus", entre os meses de março e junho de 2020, cerca de 76 pessoas distintas e 7 organizações sociais de Botucatu-SP foram cadastradas e efetivamente ajudadas por meio deste sistema. Houve 146 cadastros para ajudar pessoas ou entidades e cerca de 129 pedidos totais de ajuda. Algumas pessoas ou entidades já foram ajudadas mais de uma vez. As ajudas compreenderam doações de: cestas básicas e produtos de limpeza, gás de cozinha, além de outros produtos de primeira necessidade como fraldas, dinheiro e remédios. Houve também solicitações de ajuda para se encontrar um emprego, para se colocar correspondência no correio, para se realizar compras de alimentos e medicamentos em supermercados e farmácias, respectivamente. Nesse período, outras 9 organizações se cadastraram, mas ainda não obtiveram apoio.
} 
Há, também, uma busca mais forte da população urbana em produzir o seu próprio alimento nas cidades, com incremento na compra de sementes e mudas (PETETIN, 2020; VANINI, 2020). Assim como aumentou o interesse da população urbana em lidar com as plantas de jardinagem ou produzir alimentos em casa. A Empresa Brasileira de Pesquisa Agropecuária (EMBRAPA) lançou um curso online de hortas caseiras e obteve 18 mil inscritos em 2 turmas desde o início da pandemia no Brasil (FLORESTA URBANA, 2020).

Em função dos impactos severos da COVID-19 na saúde das pessoas, que já estavam fragilizadas pela "dieta ocidental" (ricas em gorduras saturadas, açúcares e carboidratos refinados) (BUTLER; BARRIENTOS, 2020), manifestando comorbidades, como obesidade e diabetes tipo 2, deve ganhar fôlego o trabalho de educação alimentar e nutricional realizado por organizações sociais para que a população e as políticas públicas possibilitem dietas saudáveis.

Em relação ao fechamento das escolas, parece que a COVID-19 fortalece as desigualdades no acesso aos alimentos, pois a escola de crianças de baixa renda não serve apenas à educação, mas também para a alimentação adequada (LANCKER; PAROLIN, 2020) e torna mais grave a epidemia de obesidade das crianças que estão mais tempo dentro de casa (RUNDLE et al., 2020). Esse último efeito coincide com o ganho de peso da população na quarentena, no qual $11 \%$ dos chineses e $2 \%$ dos norte-americanos relatam ganho de mais de 4,5 kg (DOU et al., 2020).

\section{A COVID-19 nos Mercados e orçamentos familiares}

Do ponto de vista dos mercados, há diversos impactos advindos da crise da COVID-19 no mundo, nos setores primário, secundário e terciário. Entre eles o desemprego em massa, a diminuição do poder de compra dos pequenos empreendimentos e da demanda por commodities e produtos manufaturados (HOBBS, 2020; NICOLA et al., 2020).

O comércio global de alimentos, pela sua essencialidade, parece ainda resistir aos efeitos de algumas rupturas ocorridas nas cadeias de suprimentos industriais (KERR, 2020). Contudo, observaram-se, em março de 2020, tendências de volatilidade nos preços futuros de trigo e de outras commodities alimentares, devido às incertezas da pandemia (VERCAMMEN, 2020).

Há, com a COVID-19, diminuição vertiginosa da demanda por alimentos em hotéis e restaurantes e maior pressão sobre trabalhadores de inspeção de espaços e transportes para comercialização de hortifrúti, com significativo aumento de custos operacionais ou eleição de áreas prioritárias em detrimento de outras também importantes; há problemas nos mercados com diminuição da capacidade de troca por grandes agentes comercializadores, observando-se 
migração de uma parte do atacado para o varejo. Essas mudanças pressionam as redes varejistas e desorganizam a cadeia de suprimentos alimentares a partir das mudanças no consumo, com impactos negativos na resiliência de todas as indústrias e serviços envolvidos (HOBBS, 2020; PETETIN, 2020).

Notórios efeitos de "compra-por-pânico e armazenagem preventiva" foram identificados em diversos lugares do mundo, o que representa desafios para a capacidade operacional de indústrias, distribuidores e especialmente comercializadores e serviços de entrega online (MUSSELL; BILYEA; HEDLEY, 2020). Houve, claramente, uma escalada nos processos de deliveries de alimentos (FAO, 2020a; DOU et al., 2020).

Efetivamente, a produção, distribuição e preços dos alimentos têm mantido tendência de aumento, que já vinha sendo verificado antes da pandemia. No geral, DOU et al. (2020) verificaram aumento significativo de preços nos alimentos que chegam aos lares na China e nos Estados Unidos durante a quarentena. De fato, o índice inflacionário brasileiro vinha mostrando uma tendência de alta dos preços dos alimentos, com cerca de $44 \%$ deles evoluindo para um nível acima da meta estipulada pelo governo (FGV, 2020).

Durante a pandemia, produtos importados ou exportados podem ser afetados a partir das dinâmicas de fechamento de fronteiras, de rupturas de algumas redes de distribuição e de aumento dos "efeitos laterais" nas cadeias de suprimento alimentar. E apesar do suprimento de produtos considerados básicos estar, em junho de 2020, mantido, as repercussões futuras oriundas de falhas nas políticas de contenção ao espalhamento rápido do vírus SARs-COV2 no Brasil ainda são desconhecidas. Há uma tendência de aumento de preços em vegetais e carnes, à medida em que as plantas processadoras de proteína animal se veem afetadas pela necessidade de lockdown e por trabalhadores doentes (HOBBS, 2020).

Siche (2020) confirma que as ações dos governos de fornecimento de alimentação à população vulnerável ou de recursos financeiros para aquisição de alimentos estão sendo reforçadas. No entanto, a demanda por alimentos é, no geral, restringida com os avanços dos efeitos da pandemia, podendo ser mais grave com a diminuição de capacidade de compra dos consumidores em função da crise econômica, o que poderá mudar o perfil dos produtos consumidos, por exemplo menos produtos industrializados e mais in natura (FAO, 2020b).

Governos e grandes distribuidores privados relatam, no geral, que não houve diminuição dos suprimentos alimentares até o momento. Na Europa, os efeitos do consumo-por-pânico foram fortemente sentidos, exigindo que o comércio fizesse mudanças drásticas, tal como restringir a quantidade de cada produto que cada indivíduo poderia comprar. Estima-se que no 
caso do Reino Unido, isso trouxe mais de 30 mil novos empregos para se atender às altas rotatividades e necessidades de reposição das prateleiras. Outra medida foi o estabelecimento de horários especiais de compras para populações vulneráveis. No varejo, ainda, houve tendência a se diminuir a variedade de produtos, focando-se no que é mais essencial para se ter em estoque comercial (NICOLA et al., 2020).

O varejo foi afetado, ainda, pela necessidade de aumento das entregas e gestão de público para se evitar aglomeração, além de ser observado ampliação da base de fornecedores para se evitar diminuição da disponibilidade de alimentos. Ao que parece, enquanto o varejo e atacado defrontam com mudanças na demanda por alimentos, cafés e restaurantes estão sendo obrigados a fechar as portas, alguns de forma permanente. A indústria de fast-food inglesa registrou mudanças, a exemplo de uma rede comercial que converteu 65 de suas lojas em cozinhas para elaboração de refeições prontas para entrega. Ao mesmo tempo, os governos do Reino Unido retiraram restrições de horários para entrega de alimentação para facilitar adaptação do setor de serviços alimentares (NICOLA et al., 2020).

Outro efeito é a diminuição das exportações intencionais causada por governos para se estabilizar/formar estoques nacionais e combater oscilações de preços de alimentos básicos, como já ocorre em países como Sérvia, Vietnam, Cazaquistão, Rússia, Cambodja, Thailândia, Índia, Indonésia, Singapura e Turquia, seja por proibição ou por ajustes relativos a novos contratos (KERR, 2020; PETETIN, 2020; TORERO, 2020; STEPHENS; MARTIN; VAN WIJK, 2020; HOSSAIN, 2020). Isso tende a diminuir a disponibilidade internacional de alimentos e levar à volatilidade dos preços dos alimentos, como na crise de 2007-2008, resultando no agravamento da crise de insegurança alimentar (PETETIN, 2020).

As restrições relacionadas as exportações internacionais estão se multiplicando em todo o mundo, embora tenha sido realizada declaração conjunta da Organização Mundial do Comércio (OMC), Organização Mundial da Saúde (OMS) e Organização das Nações Unidas para Alimentação e Agricultura (FAO) que desaconselharam tais medidas e enfatizaram a importância dos países permanecerem solidários ao objetivo comum de melhorar a alimentação e a SAN de todo o mundo (PEPETIN, 2020). Nesse esforço conjunto, é importante evitar lockdowns que afetem em demasia as dinâmicas de transporte e trabalhadores considerados essenciais, para que não se aprofunde o desperdício de alimentos no campo, como já acontece em países como Estados Unidos, Canadá, Índia, Peru, Alemanha, França, Itália e países do leste europeu e norte da África (TORERO, 2020). 
Efetivamente, o suprimento de alimentos nos mercados globais tende a cair pela diminuição geral da demanda, uma vez que o aumento do consumo para estocagem ou por pânico não contrabalanceia, igualmente, a diminuição brutal de serviços alimentares interrompidos pela pandemia (PETETIN, 2020).

Do ponto de vista do sistema alimentar internacional, ao mesmo tempo em que se age para a manutenção dos fluxos comerciais de alimentos, essa crise deixou claro que ele é altamente dependente dos fluxos globalizados das commodities alimentares. Para alguns governos e gestores, essa dependência será considerada um risco e esse fator levará a propostas de protecionismo relativo ao comércio de alimentos considerados básicos (KERR, 2020).

Os impactos COVID-19 na indústria parecem graves, enquanto o preço do petróleo desaba pela diminuição imediata da demanda e a indústria de plásticos/embalagens mostra sinais de queda abrupta das demandas, com rupturas de cadeias de suprimentos (NICOLA et al., 2020).

No setor de serviços, destacam-se os impactos ligados à educação, com próximo a 900 milhões de pessoas no mundo sendo afetadas pelo fechamento das escolas. Com isso, alimentar, nas escolas, crianças de famílias privados ao acesso regular aos alimentos se viu prejudicado. Ao mesmo tempo aumentam-se os custos de cuidados das crianças em casa. Estimativas de pesquisas realizadas nos Estados Unidos e Inglaterra estimam custo de 1 a 3\% do PIB devido ao isolamento e fechamento das escolas (RUNDLE, 2020).

De maneira geral, políticas de quarentena e isolamento diminuem o consumo e as demandas por bens e serviços (YAP, 2020). Já o mercado de TI (tecnologia de informação) está em alta, assim como a necessidade de investimentos de telecomunicações (Redes Digitais de Quinta Geração) parece mais urgente do que nunca com a COVID 19 (NICOLA et al., 2020).

Hobbs (2020) argumenta que se observa, no Canadá, crescente relevância da relação colaborativa comprador-fornecedor, mesmo diante de claras assimetrias de poder de mercado entre esses dois atores.

A COVID-19 evidencia duas transformações que já ocorrem no sistema alimentar, uma o aumento dos serviços online de entrega de comida e outra o fortalecimento das opções das cadeias locais de produção e consumo. Em relação à primeira, uma parte dos consumidores que aderiram às compras de alimentos online durante a pandemia poderá continuar valorizando e preferindo essa modalidade.

Em relação à segunda, há sinais claros de que consumidores estão fortalecendo suas predileções pelos circuitos locais de produção e consumo de alimentos, tendência que já vinha 
crescente em função de aspectos ligados à sustentabilidade. No entanto, este desejado sistema é obstaculizado pela hegemonia dos circuitos globais de alimentos que, embora impactados pela pandemia, certamente limitará o alcance das mudanças no sistema alimentar em direção ao "compre local" (HOBBS, 2020).

\section{A COVID-19 e a Ciência \& Tecnologia}

Considerando o componente de ciência e tecnologia, nota-se diminuição de recursos para ciência, tecnologia e inovação em todas as áreas da ciência, que estão sendo drenados pela demanda da crise sanitária. Em relação à circulação do conhecimento técnico-científico, a crise da COVID-19 trouxe diminuição dos eventos de intercâmbio científico no mundo, ao mesmo tempo em que a educação a distância ganhou espaço, mas sem o mesmo efeito dos eventos presenciais e com as barreiras da desigualdade no acesso às tecnologias da informação (NICOLA et al., 2020).

\section{A COVID-19 e o entorno Biofísico}

Analisando-se o componente do entorno biofísico (Natureza), percebe-se efeitos diretos e indiretos da COVID-19, a maioria deles negativos. Se, de um lado, diminuiu a emissão de gases de efeito estufa em zonas industriais, limparam-se praias e reduziram-se os ruídos, por outro, sabe-se que isso é momentâneo (WERNAU, 2020). Durante a pandemia há queda da taxa de reciclagem de resíduos e aumento da produção de resíduos orgânicos residenciais, o que eleva a possibilidade de impacto ambiental negativo sobre terras e águas (ZAMBRANOMONSERRATE; RUANO; ALCALDE, 2020).

Os efeitos da pandemia na base social e ambiental produtiva é muito diverso e varia conforme o sistema alimentar de cada país e de como ele está inserido no mercado internacional de commodities. Em sistemas alimentares mais rurais de países empobrecidos, como em alguns países da África, Ásia e América Latina, os impactos estão ligados à queda na renda e insegurança alimentar da população rural e urbana. Em países ou zonas mais industrializadas, os impactos estão mais ligados às mudanças no padrão de consumo dos alimentos nas cidades, uma vez que as refeições passaram a ser elaboradas, majoritariamente, nos lares.

Analisando-se a produção agrícola chinesa e de outros países, Siche (2020) sugere que não houve interrupção da cadeia de fornecimento como um todo, até o momento. Mas, as dificuldades com mão-de-obra estão sendo agravadas pela COVID-19 (KERR, 2020) e sua importância não deve ser minimizada (HOBBS, 2020). Esse risco também não pode ser 
desprezado em relação a caminhoneiros e trabalhadores especializados de outros equipamentos de transportes de alimentos, tais como barcaças, estações elevatórias, locomotivas e estivadores (BREWIN, 2020).

No Brasil, os agricultores que mais foram afetados negativamente com a crise da COVID-19 foram os pequenos produtores convencionais, ligados as agroindústrias ou que dependem de vendas nos mercados locais (MOURA; SOUZA, 2020) ${ }^{8}$. Já produtores locais de produtos orgânicos ou com apelos ecológicos e comercializados localmente, mostraram forte valorização durante a pandemia, sendo nítido o estímulo dado pela pandemia a iniciativas que aproximam consumidores e produtores (PETETIN, 2020).

A pandemia vem mostrando, de forma escancarada, a vulnerabilidade do atual sistema alimentar a pandemias. Isso porque os necessários lockdowns costumam afetar colheita, produção, processamento, transporte e logística, com o volume de produção tendendo a cair globalmente. O número de trabalhadores isolados está aumentando, as indústrias estão redesenhando seus locais de trabalho e gastando mais tempo em processos de higienização com possíveis paradas temporárias por falta de mão-de-obra, em especial na indústria das carnes que se vê severamente afetada em determinadas regiões e países (PETETIN, 2020).

O aumento do desperdício de alimentos pelas dificuldades logísticas, provavelmente agregará elementos para o aumento dos preços, já que há discrepância na oferta e na demanda, tal como acontece na Índia, onde os preços do arroz, farinha de trigo e leguminosas aumentaram. O problema da falta de trabalhadores para colher frutas e legumes nos campos parece também emergente, especialmente nas sociedades mais industrializadas e desenvolvidas, como Europa e América do Norte e nas regiões fornecedoras de mão-de-obra (TORERO, 2020; PETETIN, 2020).

Já em relação aos grandes produtores, no caso do Brasil há quem aponte que a COVID 19 vem estimulando as já ascendentes exportações agropecuárias brasileiras, que têm benefícios adicionais com a escalada da cotação do dólar. Além disso, a dinâmica de importação de alimentos provenientes de países europeus e asiáticos foi afetada em função da diminuição dos embarques nos portos. No caso da China, o alho é um exemplo, cuja importação caiu

\footnotetext{
${ }^{8}$ A crise mostra, de forma marcante, que o papel dos que produzem os alimentos in natura no atual sistema alimentar, muitas vezes, é pequeno, pois quando os agricultores se industrializam e se modernizam, eles passam a depender de uma intrincada cadeia de suprimentos (insumo, serviços, etc) com baixa capacidade de adaptação e mudança, como verificado durante a atual pandemia. Os atuais sistemas alimentares são altamente injustos para com os agricultores e isso é incompatível com as novas abordagens sobre os sistemas alimentares (PETETIN, 2020).
} 
acentuadamente pelo Brasil, convertendo-se, no futuro próximo, numa oportunidade para produtores brasileiros de alho (MOURA; SOUZA, 2020).

Por outro lado, enquanto a epidemia se alastra pelo interior do Brasil, o desmatamento explodiu no primeiro trimestre de 2020, por conta da crise política, sanitária, ambiental e econômica que vive o país ao mesmo tempo. O ambiente político atual vem estimulando, desde o início de 2019, as invasões de terras indígenas e outras terras públicas na região amazônica. Quem invade são grileiros, madeireiros ilegais, garimpeiros e missionários, que agem, inclusive, como vetores do novo coronavírus para o interior do Brasil (ESCOBAR, 2020). Segundo Manzano (2020), o desmatamento cresceu 63,7\% no primeiro trimestre no Brasil quando comparado com o mesmo período de 2019.

\section{A COVID-19 e as Políticas Públicas}

No âmbito das Políticas Públicas, os impactos da COVID-19 têm sido combatidos pelo poder público em todas as esferas para assegurar o funcionamento das cadeias de suprimentos de produção. As respostas para salvar o sistema financeiro da falta de liquidez também foram especialmente robustas, como na Europa, nos Estados Unidos, no Reino Unido, no Japão e na China. As políticas públicas também estão sendo demandadas para garantir alimentação adequada para a população, especialmente grupos mais vulneráveis. Governos têm doado alimentos processados e frescos e refeições preparadas (NICOLA et al., 2020).

No Canadá, se formaram "grupos de trabalho" (roundtables) para se discutir os "choques laterais" nas cadeias alimentares, com vistas a se minimizar os impactos no processamento e distribuição de alimentos (BREWIN, 2020). Em lugares onde o lockdown foi severo, já no início da pandemia, tais como Wuhan na China ou norte da Itália, os governos intervieram fortemente para sanar os problemas de especulação e falta de estoques locais, com leis que inibiram estocagens especulativas de grandes processadoras e aumentaram os estoques públicos. Foram criadas, em vários locais, forças tarefas e aplicativos para diminuir as perdas de pequenos produtores que tiveram dificuldades de escoar suas produções nos mercados locais (GALANAKIS, 2020).

Como evidenciado, a pandemia impacta profundamente a base produtiva a partir das mudanças no consumo, especialmente na agricultura familiar. Medidas emergenciais têm sido demandadas dos poderes públicos no Brasil. Medidas de curto prazo para agricultura familiar incluem: ampliar a demanda por produtos da agricultura familiar via mercados institucionais; garantir a segurança financeira e produtiva da agricultura familiar; garantir renda aos 
agricultores familiares; e regulação do sistema alimentar e de preços agrícolas. No médio prazo, incluem a retomada do Programa de Cisternas no Semiárido, Programa Nacional de Habitação Rural (PNHR) e política de reforma agrária, atualmente paralisados (VALADARES et al., 2020).

O Programa Nacional de Alimentação do Escolar (PNAE), autorizou, em caráter excepcional, durante o período de suspensão das aulas, a distribuição de gêneros alimentícios adquiridos com recursos do Programa aos pais ou responsáveis dos estudantes das escolas públicas de educação básica (BRASIL, 2020a). Além disso, o Governo Federal criou em março de 2020, uma renda de emergência para assegurar renda mínima para trabalhadores que vivem na informalidade, no valor de R \$600/mês durante um período de 3 meses (BRASIL, 2020b).

Com a COVID 19, por fim, alguns problemas já conhecidos se reapresentam de forma mais explicita, como o avanço do complexo agrícola e industrial sobre áreas naturais como acontece na América Latina, África e Ásia. O segundo é o hábito de consumo humano de animais selvagens. E o terceiro, o avanço dos sistemas agroindustriais de produção animal (VOLPATO et al., 2020).

Efetivamente, a COVID 19 trouxe desafios iminentes, de médio e longo prazo à segurança alimentar da população, contudo, a análise de países asiáticos é a de que podem ser mitigados com a implementação de políticas-chave, relacionadas a insumos agrícolas críticos (fertilizantes, sementes seguras e de qualidade) e o atendimento dos calendários sazonais das culturas, sendo que quanto mais medidas de contenção forem tomadas, mais desafiador será o processo de recuperação da estabilidade na produção, do acesso aos alimentos básicos e à nutrição e da estabilização do comércio internacional (HOSSAIN, 2020).

No Brasil, a Política Nacional de SAN possui o PLANSAN como valioso instrumento norteador para garantia e fortalecimento de ações que podem contribuir com o DHAA e a SAN. Com base no documento nacional ${ }^{9}$, o plano de estado de São Paulo pode ser capaz de impactar

\footnotetext{
${ }^{9}$ O PLANSAN-SP foi organizado de acordo com os desafios da Política Nacional de SAN no Brasil, que são: 1) Promover o acesso universal à alimentação adequada e saudável, com prioridade para as famílias e pessoas em situação de insegurança alimentar e nutricional; 2) Combater a insegurança alimentar e nutricional e promover a inclusão produtiva rural em grupos populacionais específicos, com ênfase em povos e comunidades tradicionais e outros grupos sociais vulneráveis no meio rural; 3) Promover a produção de alimentos saudáveis e sustentáveis, a estruturação da agricultura familiar e o fortalecimento de sistemas de produção de base agroecológica; 4) Promover o abastecimento e o acesso regular e permanente da população brasileira à alimentação adequada e saudável; 5) Promover e proteger a alimentação adequada e saudável da população brasileira, com estratégias de educação alimentar e nutricional e medidas regulatórias; 6) Controlar e prevenir os agravos decorrentes da má alimentação; 7) Ampliar a disponibilidade hídrica e o acesso à água para a população, em especial a população pobre no meio rural; 8) Consolidar a implementação do sistema nacional de segurança alimentar e nutricional (SISAN), aperfeiçoando a gestão federativa, a intersetorialidade e a participação social; e 9) Apoio às iniciativas de promoção da soberania, segurança alimentar e nutricional, do direito humano à alimentação adequada e de sistemas
} 
e promover melhorias nos componentes dos sistemas alimentares, uma vez que o plano pode trazer propostas de ações e monitoramento de temáticas comuns aos componentes dos sistemas alimentares saudáveis.

Dessa forma, buscaremos trazer contribuições do PLANSAN que podem mitigar os efeitos da pandemia do COVID-19, dentro dos componentes dos Sistemas Alimentares Saudáveis (UNSSCN, 2016), sendo importante mencionar que o PLANSAN-SP foi publicado para não foi implementado e tampouco vem sendo discutido pelo Governo do Estado de São Paulo, já que o Conselho Estadual de Segurança Alimentar e Nutricional (CONSEA-SP) se encontra vacante desde outubro de 2019.

\section{PLANSAN, as organizações sociais e os equipamentos públicos de proteção social}

O PLANSAN-SP propõe a ampliação das políticas públicas de acesso ao alimento por pessoas vulneráveis socialmente e de acesso dos trabalhadores a alimentos de qualidade, garantindo a universalidade de acesso à alimentação na rede pública de educação e ampliando o acesso aos programas de geração e complementação de renda no Estado de São Paulo. O Plano também prevê apoio a auto-gestão nas organizações da agricultura familiar e fortalecimento de uma rede paulista de unidades de referência em produção agroecológica pela agricultura familiar (SÃO PAULO, 2018).

O plano prevê a ampliação da visibilidade do valor social, cultural e ambiental dos alimentos, a prevenção e controle da desnutrição, carências nutricionais, obesidade, doenças não transmissíveis decorrentes da má nutrição e ingestão de agrotóxicos, além do monitoramento do perfil nutricional da população e criação de condições técnicas operacionais para o desenvolvimento do cuidado e ações de enfrentamento das doenças decorrentes da má alimentação (SÃO PAULO, 2018).

Efetivamente, o PLANSAN-SP busca outro sistema alimentar no Estado, com base na educação alimentar e nutricional em diferentes cenários de SAN e fortalecimento de medidas de regulação e monitoramento da publicidade e propaganda de alimentos e bebidas industrializados (PLANSAN-SP, 2020). A alimentação saudável e sustentável, tônica do Plano, é a base de uma resposta imune adequada a qualquer pandemia. Ainda sem dados levantados, os distúrbios na saúde decorrentes da má alimentação está, provavelmente, sobrecarregando o sistema de saúde durante a pandemia da COVID 19.

alimentares democráticos, saudáveis e sustentáveis em âmbito internacional, por meio do diálogo e da cooperação internacional (BRASIL, 2018). 
É possível perceber que os objetivos, metas e ações previstas no PLANSAN-SP auxiliam no combate aos efeitos da pandemia sobre as organizações sociais, tais como a diminuição da renda dos trabalhadores, a fragilização das organizações de pequenos agricultores familiares e o agravamento da obesidade.

\section{O PLANSAN e o Mercado}

No âmbito dos mercados, o PLANSAN-SP se propõe a incluir as comunidades tradicionais e de agricultura familiar de São Paulo nos mercados locais e regionais de produtos agroecológicos/orgânicos, fortalecendo a estrutura de crédito e estimulando a expedição/ circulação de alimentos da agricultura familiar no sentido interior-capital-interior. $\mathrm{O}$ PLANSAN-SP, se implementado, estimularia a relação direta entre produtores e consumidores locais de produtos sustentáveis, a ampliação da aquisição de alimentos orgânicos e da transição agroecológica da agricultura familiar, incluindo produtos da sociobiodiversidade, do agroextrativismo sustentável e das plantas alimentícias não convencionais (SÃO PAULO, 2018).

O fortalecimento das dinâmicas locais de produção e consumo tem lugar central no PLANSAN-SP e as ações previstas tem o potencial de melhorar a resiliência do sistema alimentar paulista, uma vez que levaria à diminuição da vulnerabilidade frente a outros estados brasileiros e nações estrangeiras que exportam para o São Paulo, além de ampliar a diversidade de alimentos frescos disponíveis para a população. As ações previstas nesse âmbito parecem enfrentar diversos problemas trazidos pela COVID 19 e que impactam negativamente os sistemas alimentares.

\section{O PLANSAN e a Ciência \& Tecnologia}

No que tange a ciência e tecnologia, o PLANSAN-SP pretende inserir o conceito de Soberania e Segurança Alimentar e Nutricional (SSAN) em todo o sistema de pesquisa-ensinoextensão do Estado, assim como prevê o fortalecimento do Sistema Estadual de C\&T\&I Agropecuária, a partir do estímulo robusto ao envolvimento de professores, pesquisadores, extensionistas e agentes de desenvolvimento com o desenvolvimento da Agroecologia e Produção Orgânica, fortalecendo o já existente Protocolo de Transição Agroecológica do Estado de São Paulo, especialmente junto a cooperativas e associações da agricultura familiar e outros pequenos e médios produtores de alimentos. O Plano objetiva fortalecer a emergência da Agroecologia como paradigma fundamental dentro das Ciências Agrárias, da Biologia, da 
Engenharia e Gestão Ambiental, do Direito Ambiental, do Jornalismo Ambiental, entre outros (SÃO PAULO, 2018).

Com novos ares paradigmáticos, o PLANSAN-SP tem a capacidade de estimular a reorganização do sistema estadual de ciência e tecnologia de modo que este possa redesenhar uma agricultura pós COVID 19, tendo como uma das bases fundamentais a Agroecologia (ALTIERI; NICHOLLS, 2020) $^{10}$.

\section{O PLANSAN e o entorno natural}

Com relação ao entorno natural (natureza), se desenvolvido, o PLANSAN-SP intensificaria as estratégias de regulamentação fundiária e adequação ambiental do Estado, especialmente das terras de agricultores familiares, pequenos produtores, assentamentos rurais e povos e comunidades tradicionais, pescadores artesanais, entre outros, inclusive no interior de Unidades de Conservação. O Plano buscaria, ao mesmo tempo, valorizar, junto a sociedade, a agrobiodiversidade (produtos, métodos e práticas tradicionais), os territórios dos povos e comunidades tradicionais e o fortalecimento da capacidade do estado de recuperar, multiplicar, melhorar e disponibilizar variedades de sementes e mudas vegetais e de raças de animais adaptadas para agricultores do estado (SÃO PAULO, 2018).

O PLANSAN-SP pretende, ainda, resolver os conflitos socioambientais entre as comunidades tradicionais e as áreas de unidades de conservação, promovendo também a agrofloresta como metodologia e recuperação e manejo sustentável dos recursos naturais. O Plano pode, se colocado em prática, reduzir o uso de agrotóxicos no Estado de São Paulo e assegurar o monitoramento da qualidade da água e dos alimentos em relação a presença de agrotóxicos, além de regulamentar, restringir e fiscalizar o uso de transgênicos alimentares e recuperar e conservar os recursos naturais do estado (SÃO PAULO, 2018).

Ainda nesse componente, o PLANSAN-SP tem um olhar especial para o fortalecimento do Ensino, da Assistência Técnica e Extensão Rural (ATER) e da Pesquisa nos/para os territórios das comunidades tradicionais, de agricultura familiar, assentados e pequenos produtores em geral. O objetivo é o de fortalecer experiências (em rede) de referências para

\footnotetext{
10 Do ponto de vista da Agroecologia, o Plano prevê o fortalecimento das capacidades municipais para o Desenvolvimento Rural Sustentável com base na Agroecologia e na Produção Orgânica em todo o Estado, com estímulos tais como: adequação da regulamentação sanitária à realidade da Agricultura Familiar, com investimentos diversos envolvendo os governos federal, estadual e municipais; fortalecimento da Transição Agroecológica nos termos da Política Estadual de Agroecologia e Produção Orgânica -PEAPO; e a disponibilização, de forma crescente, do alimento orgânico ou em transição agroecológica nas escolas públicas e outros órgãos públicos do Estado (SÃO PAULO, 2018).
} 
produção agroecológica, envolvendo toda a diversidade de produtores rurais nos territórios. O Plano incentiva o zoneamento específico e de garantia de capacitação, acesso a mercados, preços justos e insumos e sistemas localizados. Isso previne, obviamente, as falhas ligadas a dependência do mercado nacional e global de alimentos e insumos (SÃO PAULO, 2018).

O PLANSAN-SP pretende assegurar a sustentabilidade e viabilidade da produção de produtos de espécies nativas e a recuperação, conservação e proteção das nascentes e rios no Estado, garantindo qualidade e quantidade de água e melhor aproveitando das águas residuais e pluviais para reuso. Objetiva, ainda, promover a educação para o consumo responsável da água por parte do setor produtivo e do consumo residencial e a recuperação, conservação e proteção das águas subterrâneas e promover o uso mais eficiente da irrigação, garantindo o acesso da população de baixa renda no meio rural a sistemas de irrigação eficientes e de baixo custo (SÃO PAULO, 2018).

Como reconhece e fortalece os territórios de pequenos agricultores familiares (em todas as suas formas sociais), o PLANSAN-SP prevê diversas ações envolvendo questões de gênero, juventude, organização e gestão dos territórios, participação social, circuitos curtos, proteção dos bens comuns e incentivo a recuperação e desenvolvimento de recursos genéticos adaptados (SÃO PAULO, 2019).

Ações nesses campos previnem e mitigam os efeitos deletérios sobre os sistemas alimentares, já que o PLANSA-SP tem o potencial de tornar São Paulo mais soberano em sua alimentação. Isso não quer dizer que os circuitos longos (nacionais e internacionais) não devam ser fortalecidos, no sentido de antever, mitigar e adaptar o sistema alimentar aos possíveis efeitos disruptivos das pandemias sobre os sistemas alimentares.

\section{O PLANSAN e as Políticas Públicas}

No campo das políticas públicas, o PLANSAN-SP promove, efetivamente, uma ação intersetorial por parte de diversas políticas públicas do Estado, com destaques para as áreas da saúde, da educação, da agricultura e meio ambiente e da assistência social.

De acordo com o Plano, é preciso garantir que haja nos equipamentos públicos a disponibilidade e o acesso a alimentos adequados para as pessoas com necessidades alimentares especiais. E, do ponto de vista da capacidade de gerar sinergias para o enfrentamento e gestão de ameaças como a pandemia da COVID 19, o PLANSAN-SP promoveria, ostensivamente, a intersetorialidade entre as 20 secretarias envolvidas na CAISAN-SP (SÃO PAULO, 2018). 
A partir do funcionamento e fortalecimento do CONSEA-SP, o plano prevê a potencialização da adesão ao SISAN, com criação gradativa de seus componentes no Estado de São Paulo, como forma concreta de garantir a realização do DHAA, conforme artigo 6o da Constituição Brasileira (SÃO PAULO, 2018).

O Plano prevê, por fim, o monitoramento das políticas nele incluídas, a consolidação da participação popular e controle social sobre as políticas estaduais de SAN, a assessoria técnica aos municípios para adesão e operacionalização do SISAN, a realização das conferências estaduais de SAN e o funcionamento da CAISAN-SP (SÃO PAULO, 2018).

No âmbito internacional, o PLANSAN-SP busca promover a troca de experiências entre as comunidades de matriz africana brasileiras e dos países africanos da CPLP. Incentiva, ainda, a adesão do Estado a pactos internacionais para promoção da alimentação saudável, como o Pacto de Milão (SÃO PAULO, 2018).

O plano, se implementado, promoveria a inclusão do tema das mudanças climáticas na discussão sobre SAN no âmbito do Estado, do Brasil e da América Latina, incentivando, também, trabalhos relacionados à promoção da SAN dos refugiados, imigrantes e demais grupos vulneráveis (SÃO PAULO, 2018).

Apesar do PLANSAN-SP responder a diversos impactos criados pela pandemia da COVID 19 sobre os sistemas alimentares, ele não parece responder a alguns desafios criados, tais como: rupturas nas cadeias de suprimentos para agroindústrias; desemprego em massa; escassez aguda de mão-de-obra; falhas na compatibilização entre comércio internacional de alimentos e estoques nacionais; e distúrbios no funcionamento dos portos e na dinâmica internacional insumos agrícolas.

\section{Conclusão}

Ainda que não tenha sido a intenção inicial, as mudanças nas políticas públicas do Estado de São Paulo propostas pelo PLANSAN-SP se mostram adequadas ao enfrentamento de diversos efeitos negativos causados no sistema alimentar pela COVID-19, especialmente em relação a disponibilidade de alimentos, já que o Plano fortalece as capacidades de respostas locais aos ajustes necessários oriundos dos impactos globais da pandemia sobre os sistemas alimentares. O Plano também prevê metas, ações e investimentos qualitativos capazes de influir na resiliência do sistema alimentar paulista, direcionados ao fortalecimento das organizações sociais, dos mercados, da ciência e tecnologia, do entorno biofísico e das políticas públicas. 
A análise dos dados encontrados sobre os impactos da pandemia sobre os cinco componentes do sistema alimentar e o PLANSAN-SP, indicam que este plano é um valioso instrumento para promoção de ações de SAN e DHAA e, se implementado e monitorado, auxiliaria o estado no enfrentamento e mitigação dos efeitos do Covid-19. Essa contribuição se estenderia, principalmente, para o período pós pandemia, quando o país precisará se reorganizar para enfrentar as consequências econômicas e sociais deixadas pelo vírus.

\section{Referências}

ALTIERI, M. A.; NICHOLLS, C. I. Agroecology and the emergence of a post COVID-19 agriculture. Agric. Human Values, Gainesville, v. 37, p. 525-526, 2020. DOI 10.1007/s10460-020-10043-7.

ARAUJO, G.; MORAES, J. C. Restaurantes Bom Prato vão oferecer alimentação gratuita para moradores de rua cadastrados no Estado de São Paulo. Portal G1, São Paulo, 27 mai. 2020. Disponível em: https://g1.globo.com/sp/sao-paulo/noticia/2020/05/27/restaurantesbom-prato-vao-oferecer-alimentacao-gratuita-para-moradores-de-rua-cadastrados-emsp.ghtml. Acesso em: 4 jun. 2020.

ARTICULAÇÃO NACIONAL DE AGROECOLOGIA. Movimentos sociais apresentam solução emergencial de 1 bilhão para alimentar população vulnerável. Rio de Janeiro: ANA, 2020. Disponível em: https://agroecologia.org.br/2020/04/08/paa-programa-deaquisicao-de-alimentos-da-agricultura-familiar-comida-saudavel-para-o-povo/. Acesso em: 4 jun. 2020.

BRASIL. Presidência Da República, Casa Civil. Decreto nº 7.272 de 25 de agosto de 2010. Regulamenta a lei ${ }^{\circ} 11.346$, de 15 de setembro de 2006, que cria o Sistema Nacional de Segurança Alimentar e Nutricional - SISAN com vistas a assegurar o direito humano à alimentação adequada, institui a Política Nacional de Segurança Alimentar e Nutricional PNSAN, estabelece os parâmetros para a elaboração do plano nacional de segurança alimentar e nutricional, e dá outras providências. Diário Oficial da União: seção 1, Brasília, DF, p. 6 , 25 ago. 2010. Disponível em: http://www.planalto.gov.br/ccivil_03/_Ato2007-

2010/2010/Decreto/D7272.htm. Acesso em: 4 jun. 2020.

BRASIL. Ministério do Desenvolvimento Social. II Plano Nacional de Segurança

Alimentar e Nutricional: PLANSAN 2016-2019: revisado. Brasília: Câmara Interministerial de Segurança Alimentar e Nutricional (CAISAN), 2018. Disponível em:

http://www.mds.gov.br/webarquivos/arquivo/seguranca_alimentar/caisan/Publicacao/Caisan_ Nacional/PLANSAN\%202016-2019_revisado_completo.pdf. Acesso em: 4 jun. 2020.

BRASIL. Presidência da República. Lei no ${ }^{\circ}$ 13.987. Altera a Lei ${ }^{\circ} 11.947$, de 16 de junho de 2009, para autorizar distribuição de gêneros alimentícios adquiridos com recursos do Programa Nacional de Alimentação Escolar (PNAE). Diário Oficial da União: seção 1, Brasília, DF, n. 67-b, p. 9, 7 abr. 2020a. Disponível em:

http://pesquisa.in.gov.br/imprensa/jsp/visualiza/index.jsp?data=07/04/2020\&jornal=601\&pagi na $=9 \&$ totalArquivos=14. Acesso em: 10 jun. 2020 . 
BRASIL. Presidência da República. Lei no 13.982. Estabelece medidas excepcionais de proteção social a serem adotadas durante o período de enfrentamento da emergência de saúde pública de importância internacional decorrente do coronavírus (Covid-19). Diário Oficial da União: seção 1, Brasília, DF, n. 64-A, p. 1, 2 abr. 2020b. Disponível em: http://pesquisa.in.gov.br/imprensa/jsp/visualiza/index.jsp?data $=02 / 04 / 2020 \&$ jornal $=600 \&$ pagi na $=1$. Acesso em: 10 jun. 2020.

BREWIN, D. The impacts of COVID-19 on the Grains and Oilseeds Sector. Can. J. Agr. Econ., Winnipeg, v. 68, p. 185-188, 2020. DOI 10.1111/cjag.12239.

BUTLER, M. J.; BARRIENTOS, R. M. The impact of nutrition on COVID-19 susceptibility and long-term consequences. Brain, Behav. Immun., Amsterdam, v. 87, p. 53-54, 2020. DOI 10.1016/j.bbi.2020.04.040.

CARMO, M. S. A produção familiar como lócus ideal da agricultura sustentável. In: FERREIRA, A. D. D.; BRANDENBURG, A. Para pensar outra agricultura. Curitiba: Ed. UFPR, 1998. p. 218.

CASTRO, I. A extinção do Conselho Nacional de Segurança Alimentar e Nutricional e a agenda de alimentação e nutrição. Cad. Saúde Pública, Rio de Janeiro, v. 35, n. 2, p. e00009919, 2019.

DOU, Z. et al. The COVID-19 Pandemic impacting household food dynamics: a crossnational comparison of China and the U.S. SocArXiv, mai. 2020. Disponível em: https://osf.io/preprints/socarxiv/64jwy/. Acesso em: 16 jun. 2020.

ESCOBAR, A. L. A interiorização da pandemia: potenciais impactos em populações em situação de vulnerabilidade na Amazônia. NAU Soc., Salvador, v. 11, n. 20, p. 137-143, 2020. Disponível em:

https://portalseer.ufba.br/index.php/nausocial/article/view/36614/21018. Acesso em: 3 jun. 2020.

FLORESTA URBANA. Lares mais verdes: interesse por jardinagem e cultivo de hortas cresce na pandemia. Gauchazh, Porto Alegre, 15 mai. 2020. Disponível em https://gauchazh.clicrbs.com.br/fique-bem/noticia/2020/05/lares-mais-verdes-interesse-porjardinagem-e-cultivo-de-hortas-cresce-na-pandemia-cka8hwjjm00e2015nkb2a6ehx.html. Acesso em: 4 jun. 2020.

FOOD AND AGRICULTURE ORGANIZATION. FAO Director-General urges G20 to ensure that food value chains are not disrupted during COVID-19 pandemic. FAO: Roma, 2020b. Disponível em: http://www.fao.org/news/story/en/item/1268254/ico de/. Acesso em: 29 maio 2020.

FOOD AND AGRICULTURE ORGANIZATION. Índice de preços de alimentos da FAO maio de 2020. Roma: FAO, 2020c. Disponível em http://www.fao.org/worldfoodsituation/foodpricesindex/en/. Acesso em: 10 mai. 2020.

FOOD AND AGRICULTURE ORGANIZATION. Q\&A: COVID-19 pandemic - impact on food and agriculture. Roma: FAO, 2020a. Disponível em: http://www.fao.org/2019-ncov/qand-a/en/. Acesso em: 29 maio 2020.

FRANCO, J. C. If the virus doesn't kill me"...: socioeconomic impacts of COVID-19 
FUNDAÇÃO GETÚLIO VARGAS. Percentual dos itens acima da meta da inflação (IPC-Br, FGV IBRE). Portal da Inflação, São Paulo, 2020. Disponível em: https://portal-da-inflacaoibre.fgv.br/. Acesso em: 2 jun. 2020.

GALANAKIS, C. M. The food systems in the era of the coronavirus (COVID-19) pandemic crisis. Foods, Basel, v. 9, n. 4, p 523, 2020. DOI 10.3390/foods9040523.

HOBBS, J. E. Food supply chains during the COVID-19 pandemic. Special Issue Article.

Can. J. Agr. Econ., Winnipeg, v. 68, p. 171-176, 2020. DOI 10.1111/cjag.12237.

HOSSAIN, S. T. Impacts of COVID-19 on the agri-food sector: food security policies of asian productivity organization members. J. Agric. Sci., Sri Lanka, v. 15, n. 2, p. 116-132, 2020. DOI: http://doi.org/10.4038/jas.v15i2.8794.

INSTITUTO BRASILEIRO DE GEOGRAFIA E ESTATÍSTICA. Índice de preços ao consumidor amplo. Brasília: IBGE, 2020b. Disponível em: https://sidra.ibge.gov.br/ home/ipca/brasil. Acesso em: 20 maio 2020.

INSTITUTO BRASILEIRO DE GEOGRAFIA E ESTATÍSTICA. Pesquisa Nacional por amostra de domicílios contínua trimestral. Brasília: IBGE, 2020a. Disponível em: https://sidra.ibge.gov.br/pesquisa/pnadct/ tabelas. Acesso em: 12 maio 2020.

INSTITUTO GIRAMUNDO MUTUANDO. Relatório Interno de Avaliação do Sistema “A Cidade Contra o Coronavirus". Botucatu: Instituto Giramundo Mutuando, 2020. Mimeografado.

KERR, W. The COVID-19 Pandemic and agriculture - Short- and long-run implications for international trade relations: implications for international trade. Can. J. Agr. Econ., Winnipeg, v. 68, p. 225-229, 2020. DOI 10.1002/cjag. 12230.

LANCKER, W.V.; PAROLIN, Z. COVID-19, school closures and child poverty: a social crisis in the making. Lancet Public Health, Oxford, v. 5, n. p. e243-e244, 2020. Disponível em: https://doi.org/10.1016/S2468-2667(20)30084-0._Acesso em: 29 mai. 2020.

MALUF, R. S. et al. Nutrition sensitive agriculture and the promotion of food and nutrition sovereignty and security in Brazil. Cienc. Saúde Colet., Rio de Janeiro, v. 20, p. 2303-2312, 2015.

MANZANO, F. Alertas de desmatamento na Amazônia crescem 63,75\% em abril, mostram dados do Instituto Nacional de Pesquisas Espaciais (INPE). Portal G1, São Paulo, 8 maio 2020. Disponível em: https://g1.globo.com/natureza/noticia/2020/05/08/alertas-dedesmatamento-na-amazonia-crescem-em-abril-mostram-dados-do-inpe.ghtml. Acesso em: 3 jun. 2020.

MOURA, J.; SOUZA, R. Impacts of SARS-COV-2 on brazilian agribusiness. Cambridge Open Engage, p. 1-5, 2020. DOI 10.33774/coe-2020-kp2rd.

MUSSELL, A.; BILYEA, T.; HEDLEY, D. Agri-food supply chains and Covid-19: balancing resilience and vulnerability. Ontario: Agri-Food Economic Systems, 2020. Disponível em: http://www.agrifoodecon.ca/. Acesso em: 29 maio 2020.

NESHEIM, M. C. et al. A Framework for assessing effects of the food system. Washington: National Academy of Sciences, U.S. Institute of Medicine, 2015. 
NICOLA, M. et al. The socio-economic implications of the coronavirus pandemic (COVID19): a review. Int. J. Surg., London, v. 78, p. 185-193, 2020. DOI 10.1016/j.ijsu.2020.04.018

on rural working people in the Global South. Agric. Human Values, Gainesville, p. 1-2, may 2020.

PETETIN, L. The COVID-19 crisis: an opportunity to integrate food democracy into postpandemic food systems. Eur. J. Risk Regul., Berlin, v. 11, n. 2, p. 326-336, 2020. DOI 10.1017/err.2020.40.

POWER, M. et al. How COVID-19 has exposed inequalities in the UK food system: the case of UK food and poverty. Emerald Open Res., London, v. 2, n. 11, 2020.

DOI 10.35241/emeraldopenres.13539.2.

RUNDLE, A. G. et al. COVID-19 - Related school closings and risk of weight gain among children. Obesity (Silver Spring), v. 28, n. 6, p. 1008-1009, 2020.

SÃO PAULO. Governo do Estado. Plano de segurança alimentar e nutricional do Estado de São Paulo. São Paulo: CAISAN-SP, 2018. Disponível em:

https://www.consea.sp.gov.br//uploads/downloads/plasan-destaque.pdf. Acesso em: 4 jun. 2020 .

SICHE, R. What is the impact of COVID-19 disease on agriculture? Sci. Agropec., Trujillo, v. 11, n. 1, p. 3-6, 2020.

STEPHENS, E.; MARTIN, G.; VAN WIJK, M. Impacts of COVID19 on agricultural and food systems worldwide and on progress to the sustainable development goals. Agric. Syst., Barking, v. 183, p. 3-6, 2020. Editorial. Disponível em:

https://www.ncbi.nlm.nih.gov/pmc/articles/PMC7237936/pdf/main.pdf. Acesso em: 3 jun. 2020 .

SUMNER, A.; HOY, C.; ORTIZ-JUAREZ, E. Estimates of the impact of COVID-19 on global poverty. London: United Nations University, 2020. (WIDER Working Paper, 43). Disponível em: www.wider.unu.edu. Acesso em: 29 maio 2020.

TELLO, E.; GONZÁLEZ DE MOLINA, M. Methodological challenges and general criteria for assessing and designing local sustainable agri-food systems: a socio-ecological approach at landscape level. In: FRAŇKOVÁ, E.; HAAS, W.; SINGH, S. (ed.). Socio-metabolic perspectives on the sustainability of local food systems. Cham: Springer, 2017. p. 27-67. (Human Environment Interactions, v. 7). Disponível em: https://link.springer.com/chapter/10.1007/978-3-319-69236-4_2 . Acesso em: 16 jun. 2020.

TORERO, M. Without food, there can be no exit from the pandemic. Countries must join forces to avert a global food crisis from COVID-19. Nat. Res., Berlim, v. 580, p. 588-589, 2020. Disponível em: https://www.nature.com/articles/d41586-020-011813?fbclid=IwAR2HpCj1AsIkvf3yLRR-QCBCa8XWD6fIu51q7y2evH559KtJL4JrMfYVPws. Acesso em: 3 jun. 2020.

UNITED NATIONS SYSTEM STANDING COMMITTEE ON NUTRITION. Inversiones para sistemas alimentarios saludables: la implementación del marco de acción de la Segunda Conferencia Internacional sobre Nutrición. Geneva: UNSCN, 2016. Disponível 
em: https://www.unscn.org/uploads/web/news/document/ES-final-Investments-for-HealthyFood-System-UNSCN-Paper.pdf. Acesso em: 5 fev. 2020.

VANINI, E. Cresce a procura por plantas para ter natureza dentro de casa durante isolamento social: em tempos de prevenção à Covid-19, 'liberdade' ganha a cor verde. O Globo, Rio de Janeiro, 3 maio 2020. Disponível em: https://oglobo.globo.com/rio/cresce-procura-porplantas-para-ter-natureza-dentro-de-casa-durante-isolamento-social-1-24407919. Acesso em: 4 jun. 2020.

VALADARES, A. A., ALVES, F., GALIZA, M., SILVA, S.P. Agricultura Familiar e Abastecimento Alimentar no Contexto do Covid-19: uma abordagem das ações públicas emergenciais. Nota Técnica $\mathrm{N}^{\circ} 69$. Instituto de Pesquisas Econômicas - Disoc - Diretoria de Estudos e Políticas Sociais - IPEA, Abril, 2020.

VERCAMMEN, J. Information-rich wheat markets in the early days of COVID-19. Can. J. Agr. Econ., Winnipeg, v. 68, p. 177-184, 2020. Disponível em:

wileyonlinelibrary.com/journal/cjag. Acesso em: 2 jun. 2020.

VOLPATO, G. et al. Baby pangolins on my plate: possible lessons to learn from the COVID19 pandemic. J. Ethnobiol. Ethnomed., London, v. 16, n. 19, p. 1-12, 2020. DOI 10.1186/s13002-020-00366-4.

WERNAU, J. How China kept its supermarkets stocked as coronavirus raged. The Wall Street Journal, Nova York, 13 mar. 2020. Disponível em:

https://www.wsj.com/articles/how-china-fed-its-people-while-under-lockdown-11584009757 . Acesso em: 29 maio 2020.

YAP, C. W. China's factories struggle to resume operations after virus shutdown. The Wall Street Journal, New York, 8 fev. 2020. Disponível em: https://www.wsj.com/articles/chinasfactories-struggle-to-resume-operations-after-virusshutdown- 11581157800. Acesso em: 16 jun. 2020.

ZAMBRANO-MONSERRATE, M. A.; RUANO, M. A.; ALCALDE, L. S. Indirect effects of COVID-19 on the environment. Sci. Total Environm., Amsterdam, v. 728, p. 138813, 2020.

\title{
STATE OF SÃO PAULO PUBLIC POLICIES AND ORGANIZED CIVIL SOCIETY IN COPING WITH THE IMPACTS OF COVID 19 ON FOOD SYSTEMS: THE CASE OF PLANSAN-SP
}

\begin{abstract}
The article presents probable impacts from COVID-19 on 5 components of the food system: social organizations; markets; science and technology; nature (biophysical environment); and public policies. It investigates which proposals contained in the State Plan for Food and Nutritional Security of the State of São Paulo (PLANSAN-SP) can respond to these impacts, mitigating them. The impacts of COVID-19 on food systems are broad and profound, considering the different realities raised by bibliographic research. These impacts directly affect the food consumption of the population from the quarantine dynamics adopted worldwide, in
\end{abstract}


various forms, with negative effects on access and availability of food in the short, medium and long terms. PLANSAN-SP contains several proposals to guarantee the Human Right to Adequate Food (DHAA) and to stimulate Food Sovereignty and Food Nutrition and Security (SAN). The article considers that the dialogue between the organized civil society and the public power is fundamental for the construction of proposals adjusted to a diversity of challenges and realities present in the State of São Paulo. It considers also that PLANSAN-SP, if implemented and monitored could respond positively to the impacts of COVID -19 in the São Paulo food system.

Keywords: Covid 19, Plansan-SP; Food System; Public policy; Food and Nutrition Security

\title{
POLÍTICAS PÚBLICAS DEL ESTADO DE SÃO PAULO Y LA SOCIEDADE CIVIL ORGANIZADA PARA HACER FRENTE A LOS IMPACTOS DE COVID 19 EM LOS SISTEMAS ALIMENTARIOS: EL CASO DE PLANSAN-SP
}

\begin{abstract}
Resumen
El artículo presenta los probables impactos de COVID-19 en los 5 componentes del sistema alimentario: organizaciones sociales; mercados; ciencia y Tecnología; naturaleza (ambiente biofísico); y políticas públicas. E investiga qué propuestas contenidas en el Plan Estatal para la Seguridad Alimentaria y Nutricional del Estado de São Paulo (PLANSAN-SP) pueden responder a estos impactos, mitigándolos. Los impactos de COVID-19 en los sistemas alimentarios son amplios y profundos, considerando las diferentes realidades planteadas por la investigación bibliográfica. Estos impactos afectan directamente el consumo de alimentos de la población a partir de la dinámica de cuarentena adoptada en todo el mundo, en diversas formas, con efectos negativos sobre el acceso y la disponibilidad de alimentos a corto, mediano y largo plazo. PLANSAN-SP contiene varias propuestas para garantizar el derecho humano a una alimentación adecuada (DHAA) y que estimulan la soberanía alimentaria y la seguridad alimentaria y nutricional (SAN). El artículo considera que el diálogo entre la sociedad civil organizada y el poder público es fundamental para la construcción de propuestas ajustadas a una diversidad de desafíos y realidades presentes en el Estado de São Paulo y que PLANSANSP, si fuera implementado y monitoreado, podría responder positivamente a los impactos de COVID -19 en el sistema alimentario de São Paulo.
\end{abstract}

Palavras claves: Covid 19, Plansan-SP; Sistema alimentario; Política pública; Seguridad alimentaria y nutricional.

\section{Agradecimentos}

Agradecemos ao Ministério da Cidadania e ao Ministério de Ciência e Tecnologia e ao Governo do Estado de São Paulo, especialmente ao Comitê Técnico de elaboração do PLANSA-SP e ao INTERSSAN, que mostraram, na prática, que o diálogo aberto e horizontal entre agentes públicos e representantes da sociedade civil organizada e da academia na construção de políticas públicas, é o melhor caminho a seguir para que possamos a soberania alimentar. 